\title{
Decreased basal hepatic glucose uptake in impaired fasting glucose
}

\author{
Mariam Alatrach $^{1}$ - Christina Agyin ${ }^{1}$ - John Adams ${ }^{1} \cdot$ Ralph A. DeFronzo ${ }^{1}$. \\ Muhammad A. Abdul-Ghani ${ }^{1}$
}

Received: 19 September 2016 / Accepted: 11 January 2017 / Published online: 22 March 2017

(C) Springer-Verlag Berlin Heidelberg 2017

\begin{abstract}
Aims/hypothesis This research aimed to define the pathophysiological defects responsible for the elevated fasting plasma glucose (FPG) concentration and excessive rise in post-load plasma glucose observed in individuals with impaired fasting glucose (IFG).

Methods We used tracer techniques to quantify basal splanchnic (primarily hepatic) glucose uptake and glucose fluxes following glucose ingestion in individuals with normal glucose tolerance (NGT; $n=10)$ and IFG $(n=10)$.

Results Individuals with IFG had a comparable basal rate of hepatic glucose production to those with NGT $(15.2 \pm 0.2 \mathrm{vs}$ $18.0 \pm 0.8 \mu \mathrm{mol} \mathrm{min}{ }^{-1}[\mathrm{~kg} \text { lean body mass }(\mathrm{LBM})]^{-1}$; $p=0.09)$. However, they had a significantly reduced glucose clearance rate during the fasting state compared with NGT $\left(2.64 \pm 0.11\right.$ vs $3.62 \pm 0.20 \mathrm{ml} \mathrm{min}^{-1}[\mathrm{~kg} \mathrm{LBM}]^{-1}$; $p<0.01)$. The difference between the basal rate of glucose appearance measured with $\left[3-{ }^{3} \mathrm{H}\right]$ glucose and $\left[1-{ }^{14} \mathrm{C}\right]$ glucose, which represent basal splanchnic glucose uptake, was significantly reduced in IFG compared with NGT $(1.39 \pm 0.28$ vs $\left.3.16 \pm 0.44 \mu \mathrm{mol} \mathrm{min}{ }^{-1}[\mathrm{~kg} \mathrm{LBM}]^{-1} ; p=0.02\right)$. Following glucose ingestion, the total amount of exogenous glucose that appeared in the systemic circulation was not significantly
\end{abstract}

Mariam Alatrach and Christina Agyin contributed equally to this study.

Electronic supplementary material The online version of this article (doi:10.1007/s00125-017-4252-0) contains peer-reviewed but unedited supplementary material, which is available to authorised users.

Muhammad A. Abdul-Ghani

abdulghani@uthscsa.edu

1 Diabetes Division, University of Texas Health Science Center at San Antonio, 7703 Floyd Curl Drive, San Antonio, TX 78229, USA different between groups. However, suppression of endogenous glucose production (EGP) was markedly impaired in individuals with IFG.

Conclusions/interpretation These results demonstrate that decreased tissue (liver) glucose uptake, not enhanced EGP, is the cause for elevated FPG concentration in individuals with IFG, while the excessive rise in plasma glucose concentration following a glucose load in these individuals is the result of impaired suppression of hepatic glucose production.

Keywords Hepatic glucose production $\cdot$ Hepatic glucose uptake $\cdot$ Impaired fasting glucose
Abbreviations
bEGP Basal rate of endogenous glucose production
EGP Endogenous glucose production
FPG Fasting plasma glucose
HGU Hepatic glucose uptake
IFG Impaired fasting glucose
IGT Impaired glucose tolerance
LBM Lean body mass
NGT Normal glucose tolerance
$\mathrm{R}_{\mathrm{a}} \quad$ Rate of appearance
rEGP Residual rate of endogenous glucose production
$\mathrm{R}_{\mathrm{a}} \mathrm{O} \quad$ Rate of appearance of oral glucose
$\mathrm{R}_{\mathrm{a}} \mathrm{T}$ Total rate of appearance of glucose in the systemic circulation

\section{Introduction}

Impaired fasting glucose (IFG), defined as fasting plasma glucose (FPG) at 5.6-7.0 mmol/1, was introduced by the ADA in 1997 as an intermediate stage in glucose tolerance, between 
normal glucose tolerance (NGT) and overt type 2 diabetes mellitus [1]. This category of disease was meant to identify individuals at increased future risk of type 2 diabetes mellitus without the need for an OGTT. Compared with those with NGT, individuals with IFG, such as those with impaired glucose tolerance (IGT), manifest a fivefold greater risk of progression to type 2 diabetes [2]. Many previous studies [3-9] have documented distinct metabolic abnormalities in IFG and IGT. Individuals with IGT manifest severe insulin resistance in skeletal muscle and impaired second phase insulin secretion, while those with IFG manifest normal/near normal insulin sensitivity in skeletal muscle and impaired first phase insulin secretion [3-9]. Because insulin-mediated muscle glucose uptake is the principal factor responsible for the disposal of a glucose load, the combination of severe muscle insulin resistance and impaired second phase insulin secretion explains the elevated $2 \mathrm{~h}$ plasma glucose concentration observed in IGT individuals [3, 4]. Conversely, the normal/near normal insulin sensitivity in skeletal muscle and normal second phase insulin secretion in individuals with IFG explains why the $2 \mathrm{~h}$ plasma glucose concentration returns to starting fasting, albeit elevated, levels in these patients [3, 4].

Despite the return of $2 \mathrm{~h}$ plasma glucose concentration to the starting fasting level in patients with IFG, there is an excessive rise in the plasma glucose concentration after a glucose load, e.g. at 60 and 75 min during an OGTT and mixed meal tests [3]. We previously demonstrated that the $1 \mathrm{~h}$ plasma glucose concentration during an OGTT is the strongest predictor of future type 2 diabetes risk, independent of glucose tolerance status $[10,11]$, and that individuals with IFG with a $1 \mathrm{~h}$ plasma glucose $>8.6 \mathrm{mmol} / \mathrm{l}$ manifest a fourfold greater risk of future type 2 diabetes than those with IFG and $1 \mathrm{~h}$ plasma glucose levels $<8.6 \mathrm{mmol} / 1[10,12]$. Thus, it is important to identify the metabolic abnormality responsible for the excessive post-load rise in plasma glucose concentration in individuals with IFG. Although the double-tracer technique is widely used to assess the contribution of exogenous glucose absorption vs endogenous glucose production (EGP) to the elevation in plasma glucose concentration following glucose ingestion in type 2 diabetes patients [13-16], no previous study has used this technique to examine the source of the excessive rise in plasma glucose concentration following glucose ingestion in individuals with IFG.

Despite a wealth of previous studies [3-9, 17-22] that have examined the pathophysiology of IFG and identified multiple metabolic defects, including hepatic insulin resistance and impaired first phase insulin secretion, none of these defects explain the elevated FPG concentration in individuals with IFG. The basal rate of EGP (bEGP) is the principal determinant of FPG concentration [23]. We [4] and others [6-8] have previously demonstrated that individuals with IFG manifest moderate to severe hepatic insulin resistance. However, elevated fasting plasma insulin concentration offsets hepatic insulin resistance and maintains the bEGP in the normal range [24]. Indeed the vast majority [4-9, 17, 18], though not all [19, 22], previous studies have failed to document a significant rise in bEGP in individuals with IFG compared with NGT. Of note, some investigators who reported an elevated bEGP in IFG in some studies $[19,22]$ also reported a normal bEGP in others $[6$, $9,18]$. Moreover, even in individuals with type 2 diabetes, the increase in bEGP becomes evident only when FPG concentration exceeds $\sim 8.9 \mathrm{mmol} / 1[23,24]$. A normal bEGP in individuals with IFG in the presence of an elevated FPG concentration suggests decreased glucose clearance rate. Consistent with this hypothesis, we have previously demonstrated that participants with IFG manifest a decreased basal rate of glucose clearance during the fasting state [25].

Under fasting conditions, the majority of basal glucose uptake $\left(\sim 11.1 \mu \mathrm{mol} \mathrm{kg} \mathrm{kg}^{-1} \mathrm{~min}^{-1}\right)$ takes place in insulinindependent tissues. Approximately one half of basal glucose uptake $\left(\sim 5.55 \mu \mathrm{mol} \mathrm{kg}{ }^{-1} \mathrm{~min}^{-1}\right)$ occurs in the brain [26], while the other half is taken up in an insulin-independent manner, approximately equally by the skeletal muscle and liver [26]. The aim of the present study was to examine whether the reduced rate of basal splanchnic (primarily hepatic [HGU]) glucose uptake in participants with IFG contributes to the decreased rate of basal glucose clearance in individuals with IFG.

\section{Methods}

Study participants Ten individuals with NGT and ten individuals with isolated IFG (according to the ADA criteria [1]) participated in the present study. All individuals were in good general health as determined by their medical history, physical examination and screening blood tests. Participants did not take part in heavy exercise programmes or took any medication known to affect glucose tolerance. Weight was stable $( \pm 1.4 \mathrm{~kg})$ over the 3 months prior to the study. The study protocol was approved by the University of Texas Health Science Center at San Antonio Institutional Review Board (UTHSCSA IRB) and informed written consent was obtained from all individuals prior to their participation.

Study design All studies were performed in the morning at the Clinical Research Center at the Texas Diabetes Institute (San Antonio TX, USA), after a 10-12 h overnight fast. Each participant underwent the following tests, each performed on a separate day with an interval of 1-3 weeks: (1) a 2 h, $75 \mathrm{~g}$ OGTT to document glucose tolerance status; (2) a dual-energy x-ray absorptiometry (DEXA) scan (GE, Boston, MA, USA) to quantify total body fat and lean body mass (LBM); (3) a $4 \mathrm{~h}$ double-tracer $75 \mathrm{~g}$ OGTT to quantify the rates of exogenous glucose appearance and EGP; and (4) an oral-i.v. double- 
tracer infusion study to quantify the basal rate of splanchnic glucose uptake (i.e. HGU).

Double-tracer OGTT test A 4 h 75 g OGTT was performed after a $10 \mathrm{~h}$ overnight fast [13]. Individuals were admitted to the Clinical Research Center at 07:00 hours and catheters were placed in each antecubital vein for blood withdrawal and infusion of test substances. At 07:30 hours a primed $(925,000 \mathrm{~Bq})$-continuous $(9250 \mathrm{~Bq} / \mathrm{min})$ infusion of $\left[3-{ }^{3} \mathrm{H}\right]$ glucose (Perkin Elmer, Waltham, MA, USA) was started and continued until the study end, at 13:30 hours. After a $2 \mathrm{~h}$ tracer equilibration period (at 09:30 hours), individuals ingested $75 \mathrm{~g}$ of glucose containing 3,700,000 Bq of $\left[1-{ }^{14} \mathrm{C}\right]$ glucose (Perkin Elmer), which was diluted in $300 \mathrm{ml}$ of orange-flavoured water (Thermo Scientific, Waltham, MA, USA). After glucose ingestion, blood samples were obtained every 15-30 min for $4 \mathrm{~h}$ for the determination of plasma $\left[1-{ }^{14} \mathrm{C}\right]$ glucose and $\left[3-{ }^{3} \mathrm{H}\right]$ glucose radioactivity levels and plasma glucose, insulin, and glucagon concentrations.

Oral-i.v. double-tracer infusion test Individuals were admitted to the Clinical Research Center at 07:00 hours and catheters were placed into each antecubital vein for blood withdrawal and infusion of test substances. A nasoduodenal tube was placed and advanced to the duodenum guided by the CORTRAK (CORPAK MedSystem, MedSystem, Buffalo Grove, IL, USA). The placement of the tube was confirmed by abdominal x-ray (GE, Boston, MA, USA). At 07:30 hours, a primed $(925,000 \mathrm{~Bq})$-continuous $(9250 \mathrm{~Bq} / \mathrm{min})$ infusion of $\left[3-{ }^{3} \mathrm{H}\right]$ glucose (dissolved in saline $[154 \mathrm{mmol} / \mathrm{l} \mathrm{NaCl}]$ ) was started via the i.v. catheter and a primed $(925,000 \mathrm{~Bq})$-continuous $(9250 \mathrm{~Bq} / \mathrm{min})$ infusion of $\left[1-{ }^{14} \mathrm{C}\right]$ glucose (dissolved in saline) was started via the nasoduodenal tube. A total of $10 \mathrm{nmol}$ of glucose was infused during the study. After a $120 \mathrm{~min}$ tracer equilibration period, blood samples were obtained every $10 \mathrm{~min}$ from 120 to $180 \mathrm{~min}$ for determination of plasma $\left[1-{ }^{14} \mathrm{C}\right]$ glucose and $\left[3-{ }^{3} \mathrm{H}\right]$ glucose radioactivity levels and plasma glucose concentration.

Analytical determinations Plasma glucose concentration was determined by the glucose oxidase method (Analox Glucose Analyzer; Analox Instruments, Lunenburg, MA, USA). Plasma insulin and glucagon concentrations were determined by radioimmunoassay (Diagnostic Products, Los Angeles, CA, USA).

Plasma $\left[3-{ }^{3} \mathrm{H}\right]$ glucose and $\left[1-{ }^{14} \mathrm{C}\right]$ glucose radioactivity levels were determined by the Somogyi procedure, as previously described [4, 13]. Briefly, a plasma sample was deproteinised with barium hydroxide and zinc sulphate. The deproteinised supernatant fraction was then evaporated to dryness to remove ${ }^{3} \mathrm{H}_{2} \mathrm{O}$, reconstituted with water, and radioactivity was counted.
Calculations and statistical analysis During the doubletracer OGTT test, the bEGP was calculated as $\left[3-{ }^{3} \mathrm{H}\right]$ glucose infusion rate $(\mathrm{dpm} / \mathrm{min})$ divided by the steady-state plasma $\left[3-{ }^{3} \mathrm{H}\right]$ glucose specific activity $(\mathrm{dpm} / \mu \mathrm{mol})$. After glucose ingestion, non-steady-state conditions for plasma glucose concentration prevail, during which the total rate of appearance $\left(R_{a}\right)$ of glucose in the systemic circulation $\left(\mathrm{R}_{\mathrm{a}} \mathrm{T}\right)$ was computed from the change in plasma [3-3H]glucose specific activity using Steele's equation, as previously reported [4, 13]. The $\left[1-{ }^{14} \mathrm{C}\right]$ glucose data were used to calculate the $\mathrm{R}_{\mathrm{a}}$ of oral glucose $\left(\mathrm{R}_{\mathrm{a}} \mathrm{O}\right)$. After glucose ingestion, residual rate of EG-P (rEGP) was calculated as the difference between $\mathrm{R}_{\mathrm{a}} \mathrm{T}$ and $\mathrm{R}_{\mathrm{a}} \mathrm{O}$ [13].

During the oral-i.v. double-tracer infusion study, the bEGP was calculated for $\left[3-{ }^{3} \mathrm{H}\right]$ glucose by dividing $\left[3-{ }^{3} \mathrm{H}\right]$ glucose infusion rate $(\mathrm{dpm} / \mathrm{min})$ by the steady-state plasma $\left[3-{ }^{3} \mathrm{H}\right]$ glucose specific activity $(\mathrm{dpm} / \mu \mathrm{mol})$. The $\mathrm{R}_{\mathrm{a}}$ of $\left[1-{ }^{14} \mathrm{C}\right]$ glucose was calculated as the $\left[1-{ }^{14} \mathrm{C}\right]$ glucose tracer infusion rate $(\mathrm{dpm} / \mathrm{min})$ divided by the steady-state plasma $\left[1-{ }^{14} \mathrm{C}\right]$ glucose specific activity $(\mathrm{dpm} / \mu \mathrm{mol})$. Only the $\left[1-{ }^{14} \mathrm{C}\right]$ glucose that escapes the liver and non-hepatic splanchnic tissues appears in the systemic circulation, while all infused $\left[3-{ }^{3} \mathrm{H}\right]$ glucose appears in the systemic circulation. Therefore, the difference between $\mathrm{R}_{\mathrm{a}}$ of [3- $\left.{ }^{3} \mathrm{H}\right]$ glucose and $\mathrm{R}_{\mathrm{a}}$ of $\left[1-{ }^{14} \mathrm{C}\right]$ glucose represents the basal rate of hepatic plus non-hepatic splanchnic tissue glucose uptake. Because the absorption of glucose from the duodenum is rapid, we assumed that the rate of absorption of $\left[1-{ }^{14} \mathrm{C}\right]$ glucose was constant. Consistent with this assumption, electronic supplementary material (ESM) Fig. 1 demonstrates that from 120-180 min after the start of tracer infusion, the specific activity of $\left[1-{ }^{14} \mathrm{C}\right]$ glucose, as well as $\left[3-{ }^{3} \mathrm{H}\right]$ glucose, in the circulation was stable over time, confirming the presence of steady-state conditions for both $\left[1-{ }^{14} \mathrm{C}\right]$ glucose and $\left[3-{ }^{3} \mathrm{H}\right]$ glucose. Because the majority of glucose uptake occurs in lean tissues, and to account for the small, albeit not significant, difference in BMI between the IFG and NGT groups, $\mathrm{R}_{\mathrm{a}}$ is expressed as $\mu \mathrm{mol} \min ^{-1}[\mathrm{~kg} \mathrm{LBM}]^{-1}$.

Data are presented as mean \pm SEM. Differences between means were tested with Student's $t$ test; statistical significance was set at $p<0.05$.

\section{Results}

Participant characteristics As per study design, individuals with IFG had a significantly higher FPG concentration than individuals with NGT $(5.83 \pm 0.11$ vs $4.94 \pm 0.11 \mathrm{mmol} / \mathrm{l}$, respectively; $p<0.0001)$. NGT and IFG groups were well matched for age $(31 \pm 4$ vs $38 \pm 5$ years, respectively; $p=0.48$ ) and sex (female/male: $6 / 4$ in NGT vs $4 / 6$ in IFG). BMI did not significantly differ between the two groups (NGT: $30.7 \pm 1.1 \mathrm{~kg} / \mathrm{m}^{2}$; IFG: $28.6 \pm 2.1 \mathrm{~kg} / \mathrm{m}^{2} ; p=0.18$ ). Body fat per cent was similar in the two groups (NGT: $0.328 \pm 0.05$; IFG: $0.321 \pm 0.04$ ). Importantly, the $2 \mathrm{~h}$ plasma 
glucose concentration during the OGTT was similar in IFG and NGT individuals $(6.28 \pm 0.28$ vs $5.94 \pm 0.18 \mathrm{mmol} / \mathrm{l}$, respectively, $p=0.38$ ).

Fasting splanchnic glucose uptake During the oral-i.v. double-tracer infusion study, the bEGP (primarily reflecting hepatic glucose production) was measured using $\left[3-{ }^{3} \mathrm{H}\right]$ glucose and was not significantly different in individuals with IFG vs those with NGT (mean bEGP \pm SEM: $15.2 \pm 0.2$ vs $18.0 \pm 0.8 \mu \mathrm{mol} \mathrm{min}^{-1}[\mathrm{~kg} \mathrm{LBM}]^{-1} ; p=0.09$; Fig. 1a), while the basal glucose clearance rate was significantly reduced in individuals with IFG vs NGT $(2.64 \pm 0.11$ vs $\left.3.62 \pm 0.20 \mathrm{ml} \mathrm{min}^{-1}[\mathrm{~kg} \mathrm{LBM}]^{-1} ; p<0.01\right)$. For each participant in each group, the basal rate of glucose appearance was lower when measured using $\left[1-{ }^{14} \mathrm{C}\right]$ glucose than when measured using $\left[3-{ }^{3} \mathrm{H}\right]$ glucose (Fig. 1a). Basal $\mathrm{R}_{\mathrm{a}}$, as measured with $\left[1-{ }^{14} \mathrm{C}\right]$ glucose, was $14.87 \pm 0.61 \mu \mathrm{mol} \mathrm{min}{ }^{-1}[\mathrm{~kg} \mathrm{LBM}]^{-1}$ for individuals with NGT $(p<0.0001$ vs bEGP measured using $\left[3-{ }^{3} \mathrm{H}\right]$ glucose), while in those with IFG it was $14.00 \pm 0.30 \mu \mathrm{mol} \mathrm{min}^{-1}[\mathrm{~kg} \mathrm{LBM}]^{-1}(p=0.002$ vs bEGP measured using $\left[3-{ }^{3} \mathrm{H}\right]$ glucose). The difference in $\mathrm{R}_{\mathrm{a}}$ measured with $\left[3-{ }^{3} \mathrm{H}\right]$ glucose and $\mathrm{R}_{\mathrm{a}}$ measured with $\left[1-{ }^{14} \mathrm{C}\right]$ glucose, which represents the basal rate of splanchnic (hepatic plus non-hepatic splanchnic tissues) glucose uptake was significantly lower in IFG vs NGT individuals $(1.39 \pm 0.28$ vs $3.16 \pm 0.44 \mu \mathrm{mol} \mathrm{min}{ }^{-1}[\mathrm{~kg} \mathrm{LBM}]^{-1} ; p=0.02$; Fig. 1b). Further, the basal rate of splanchnic glucose uptake strongly and inversely correlated with the FPG concentration $(r=-0.72, p<0.001$; Fig. 1c).

Glucose kinetics following oral glucose load In individuals with IFG, the plasma glucose concentration between 45 and 105 min following glucose ingestion increased to significantly higher values than in individuals with NGT (Fig. 2a). The peak plasma glucose concentration was reached at $45 \mathrm{~min}$ in both groups and was $1.3 \mathrm{mmol} / \mathrm{l}$ higher in individuals with IFG vs NGT $(10.3 \pm 0.5$ vs $9.0 \pm 0.4 \mathrm{mmol} / \mathrm{l} ; p<0.05)$. However, the $2 \mathrm{~h}$ plasma glucose concentration was comparable in both groups $(7.5 \pm 0.2$ vs $7.2 \pm 0.3 \mathrm{mmol} / 1 ; p=0.42)$,
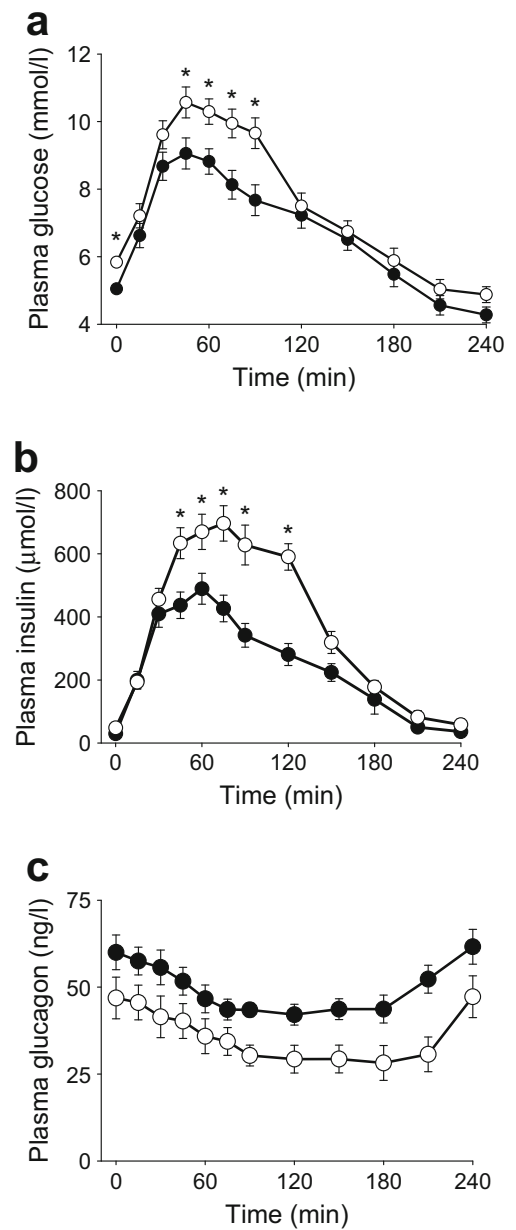

Fig. 2 (a) Plasma glucose concentration, (b) plasma insulin concentration and (c) plasma glucagon concentration during the double-tracer OGTT in individuals with NGT (black circles) and IFG (white circles). Data are presented as mean \pm SEM. $* p<0.05$

as was the plasma glucose concentration between 2 and $4 \mathrm{~h}$ during the OGTT. Plasma insulin concentration between 45 and 120 min was also significantly greater in IFG vs NGT individuals (Fig. 2b). On the other hand, fasting plasma glucagon concentration did not significantly differ between the two groups (IFG vs NGT: $47 \pm 3$ vs $60 \pm 4 \mathrm{ng} / \mathrm{l} ; p=0.31$ ) and a

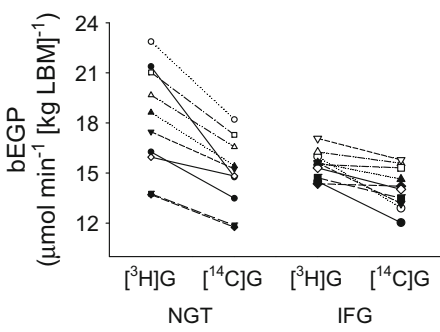

b

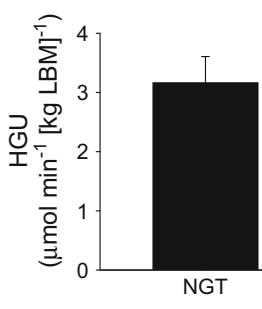

Fig. 1 (a) EGP measured using $\left[3-{ }^{3} \mathrm{H}\right]$ glucose $\left(\left[3-{ }^{3} \mathrm{H}\right] \mathrm{G}\right)$ and $\left[1-{ }^{14} \mathrm{C}\right]$ glucose $\left(\left[1-{ }^{14} \mathrm{C}\right] \mathrm{G}\right)$ in individuals with NGT and IFG. (b) Basal HGU in individuals with NGT and IFG, measured as the difference between the basal rate of glucose appearance measured with $\left[3-{ }^{3} \mathrm{H}\right]$ glucose

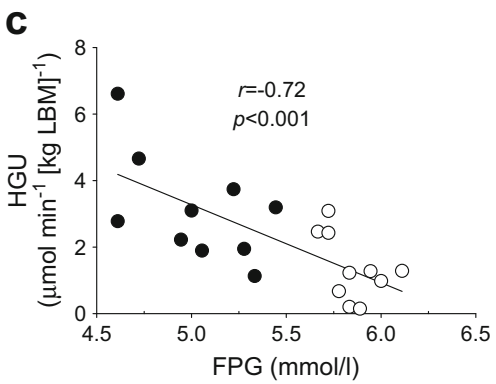

and $\left[1-{ }^{14} \mathrm{C}\right]$ glucose. (c) The relationship between basal rate of HGU and FPG concentration in individuals with NGT (black circles) and IFG (white circles) $(r=-0.72, p<0.001)$. Data are presented as individual data points or mean + SEM. ${ }^{\dagger} p=0.02$ 
the decrement in plasma glucagon concentration during the OGTT was comparable in both groups (Fig. 2c). Thus, the fasting insulin:glucagon ratio was significantly higher in IFG vs NGT individuals $(0.14 \pm 0.03$ vs $0.05 \pm 0.01 ; p<0.05)$, and this ratio increased to $2.26 \pm 0.38$ vs $1.10 \pm 0.18$, between 0 and $120 \min (p=0.006$;).

Since the plasma glucose concentration was comparable in both IFG and NGT groups after 120 min during the OGTT (Fig. 2a), we calculated the amount of glucose that appeared in the systemic circulation during the initial $0-120 \mathrm{~min}$ of the OGTT. From 0-120 min after glucose ingestion, $\mathrm{R}_{\mathrm{a}} \mathrm{T}$ was significantly greater in individuals with IFG vs NGT $(0.29 \pm 0.02$ vs $0.24 \pm 0.01 \mathrm{~mol} ; p=0.01$; Table 1$)$. Despite the greater $\mathrm{R}_{\mathrm{a}} \mathrm{T}$ in individuals with IFG, $\mathrm{R}_{\mathrm{a}} \mathrm{O}$ between 0 and 120 min was not significantly different between groups (NGT vs IFG: $0.22 \pm 0.01$ vs $0.20 \pm 0.02 \mathrm{~mol} ; p=0.73$; Table 1 ). Thus, the portion of the ambient plasma glucose concentration originating from ingested glucose was similar in IFG and NGT groups (Fig. 3a). Conversely, at 45-120 min of the double-tracer OGTT, the suppression of bEGP in individuals with IFG was significantly impaired compared with those with NGT (Fig. 3b). Furthermore, the amount of glucose produced by the liver (rEGP) between 0 and 120 min was significantly greater in individuals with IFG vs NGT $(0.06 \pm 0.02$ vs $0.02 \pm 0.01 \mathrm{~mol}, p=0.008$, Table 1$)$. Also, rEGP between 0 and 120 min significantly and inversely correlated with the basal rate of splanchnic glucose uptake $(r=-0.41, p<0.05)$. Thus, the portion of ambient plasma glucose concentration originating from the liver after glucose ingestion was significantly higher in IFG vs NGT individuals (Fig. 3c).

Mean fasting plasma NEFA concentration was similar in both groups (IFG vs NGT: $0.49 \pm 0.05$ vs $0.46 \pm 0.04 \mathrm{mmol} / \mathrm{l}$, $p=0.78$ ). Because individuals with IFG had significantly greater increases in fasting plasma insulin concentration during the OGTT than those with NGT (Fig. 2b), the adipocyte insulin resistance index (the product of fasting plasma insulin concentration and fasting plasma NEFA concentration) was significantly greater in individuals with IFG (data not shown). Despite higher plasma insulin concentration during the OGTT in participants with IFG, the suppression of plasma NEFA concentration after glucose ingestion was significantly greater in individuals with NGT at 30 and 60 min (Fig. 4).

Table 1 Glucose fluxes during 0-120 min of the OGTT in individuals with IFG and NGT

\begin{tabular}{llll}
\hline Variable & NGT & IFG & $p$ value \\
\hline $\mathrm{R}_{\mathrm{a}} \mathrm{T}(\mathrm{mol})$ & $0.24 \pm 0.01$ & $0.29 \pm 0.02$ & 0.01 \\
$\mathrm{R}_{\mathrm{a}} \mathrm{O}(\mathrm{mol})$ & $0.22 \pm 0.01$ & $0.20 \pm 0.02$ & 0.73 \\
$\mathrm{rEGP}(\mathrm{mol})$ & $0.02 \pm 0.01$ & $0.06 \pm 0.02$ & 0.008 \\
\hline
\end{tabular}
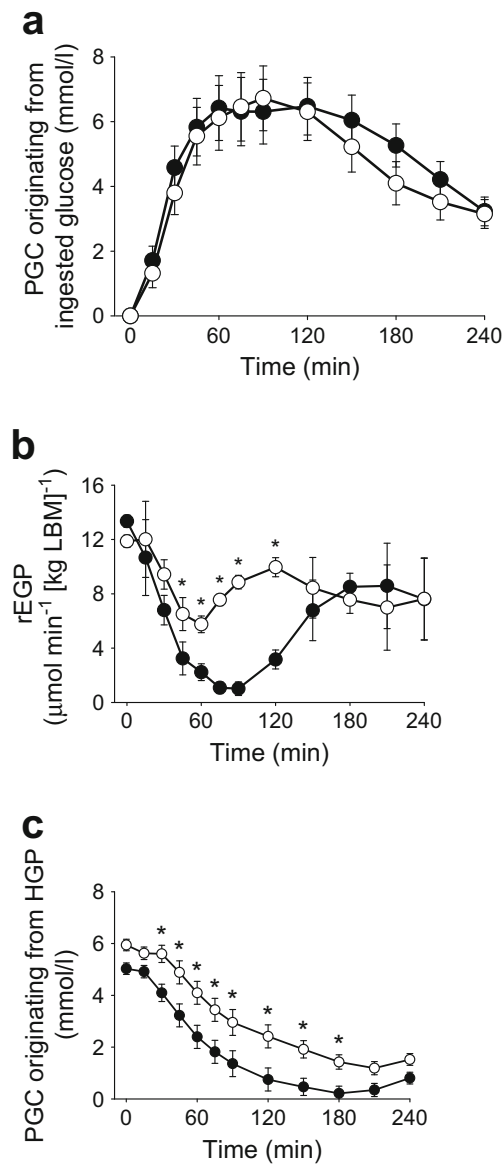

Fig. 3 Origin of plasma glucose concentration in IFG and NGT. (a) Plasma glucose concentration originating from ingested glucose during the OGTT in individuals with IFG and NGT. (b) The rate of rEGP measured with $\left[3-{ }^{3} \mathrm{H}\right]$ glucose during a double-tracer OGTT in individuals with IFG and NGT. (c) Plasma glucose concentration originating from hepatic glucose production. NGT, black circles; IFG, white circles. HGP, hepatic glucose production; PGC, plasma glucose concentration. Data are presented as mean \pm SEM. $* p<0.05$

\section{Discussion}

The results of the present study provide two major novel observations that help to elucidate the disturbances in basal and post-load glucose fluxes responsible for fasting and postprandial hyperglycaemia, respectively, in individuals with IFG. The

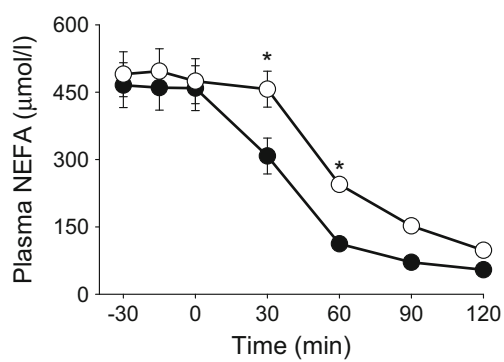

Fig. 4 Plasma NEFA concentration during the OGTT in individuals with IFG (white circles) and NGT (black circles). Data are presented as mean \pm SEM. $* p<0.05$ 
first major finding is that, compared with individuals with NGT, those with IFG manifest a decreased rate of splanchnic (hepatic plus non-hepatic splanchnic tissues) glucose uptake during the fasting state. The basal rate of splanchnic glucose uptake (measured with an oral-i.v. double-tracer infusion technique) was $3.16 \mu \mathrm{mol} \mathrm{min}^{-1}[\mathrm{~kg} \mathrm{LBM}]^{-1}$ in individuals with NGT. This is comparable to the basal rate of splanchnic glucose uptake measured using hepatic vein catheterisation [27], and it was reduced by $56 \%$ in IFG individuals. Since bEGP measured with $\left[3-{ }^{3} \mathrm{H}\right]$ glucose represents the total rate of cold glucose entering the circulation (primarily from the liver), the difference between bEGP (measured with $\left[3-{ }^{3} \mathrm{H}\right]$ glucose) and basal splanchnic glucose uptake (primarily reflecting HGU) represents the net splanchnic (hepatic) glucose balance and was calculated as $14.87 \mu \mathrm{mol} \mathrm{min}{ }^{-1}[\mathrm{~kg} \mathrm{LBM}]^{-1}$ in individuals with NGT. Although individuals with IFG had a significantly lower rate of splanchnic glucose uptake in the fasting state compared with individuals with NGT (1.39 vs $3.16 \mu \mathrm{mol} \mathrm{min}{ }^{-1}[\mathrm{~kg} \mathrm{LBM}]^{-1}$, respectively; $p=0.02$ ), the net splanchnic glucose balance in participants with IFG $\left(14.00 \mu \mathrm{mol} \mathrm{min}{ }^{-1}[\mathrm{~kg} \mathrm{LBM}]^{-1}\right)$ was comparable to those

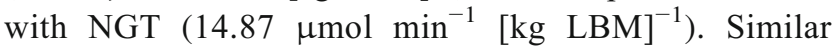
splanchnic glucose balance in individuals with IFG in the presence of an elevated FPG concentration, fasting hyperinsulinaemia and lower fasting plasma glucagon concentration, indicates impaired suppression of hepatic glucose production by the combined effects of glucose and insulin, i.e. hepatic insulin resistance. The decreased basal rate of splanchnic glucose uptake observed in participants with IFG is consistent with the decreased basal glucose clearance previously reported by our lab [25] and suggests that the elevated FPG concentration in these individuals is not due to increased glucose production by the liver during sleep, but rather is the result of decreased splanchnic (primarily hepatic) glucose uptake during sleeping hours in the presence of a 'normal' rate of EGP. Of note, splanchnic glucose uptake is insulin independent and is primarily determined by hepatic glucokinase activity. Consistent with this, a recent study [28] demonstrated decreased hepatic glucokinase activity in individuals with IFG.

The second major novel finding in the present study is that the excessive rise in plasma glucose concentration in individuals with IFG following glucose ingestion is not due to an increased rate of glucose absorption (Fig. 3a) but is rather a result of impaired suppression of EGP (Fig. 3b). Participants with IFG had a significantly greater rise in plasma glucose concentration during the initial 45-120 min of the OGTT, compared with the NGT group (Fig. 2a). This rise in plasma glucose concentration has resulted from an increased $\mathrm{R}_{\mathrm{a}} \mathrm{T}$ (Table 1). Between 0 and 120 min following glucose ingestion, more glucose $(8 \mathrm{~g})$ appeared in the systemic circulation in individuals with IFG than in NGT. This excess glucose appearance likely has contributed to the excessive rise in plasma glucose concentration.
The present study also identified the source of the excess glucose appearance in individuals with IFG. No significant difference was observed in the rate of ingested glucose appearance $\left(\mathrm{R}_{\mathrm{a}} \mathrm{O}\right)$ in the systemic circulation in the IFG vs NGT group (Table 1). The portion of the ambient plasma glucose concentration originating from ingested glucose was similar in IFG and NGT groups (Fig. 3a). Conversely, the suppression of EGP between 0 and 120 min following glucose ingestion was impaired in individuals with IFG vs NGT and resulted in the 'addition' of an excess $\sim 56 \mathrm{mmol}$ of glucose in the circulation (Table 1). Thus, impaired suppression of EGP was the primary cause of postprandial hyperglycaemia in individuals with IFG. Of note, the impaired suppression of EGP in IFG was present despite significantly higher plasma insulin (Fig. 2b) and significantly higher plasma insulin:glucagon ratio, emphasising the severity of hepatic insulin resistance in individuals with IFG. We $[4,25]$ and others $[5-8,28]$ have previously shown that the ability of insulin to suppress EGP is impaired in individuals with IFG. The impaired suppression of EGP following glucose ingestion in participants with IFG in the present study is consistent with these findings and extends them by demonstrating that this impairment in EGP suppression leads to the excessive rise in plasma glucose concentration observed in these individuals following glucose ingestion.

Although individuals with IFG and NGT had comparable fasting plasma NEFA concentration, those with IFG manifest insulin resistance in adipocytes. This was evident by the significantly elevated adipocyte insulin resistance index observed in the participants with IFG, both during the fasting state and after glucose ingestion (data not shown), and in the impaired suppression of plasma NEFA concentrations at 30 and 60 min during the OGTT (Fig. 4). Because in general, individuals spend most of the day in the fed state, it is possible that impaired NEFA suppression in IFG subjects results in a greater supply of NEFA to the liver, which may had contributed to the impairment in hepatic glucose metabolism (impaired HGU and suppression of EGP). Although HGU is insulin independent, the inverse relationship between rEGP and HGU (data not shown) may suggest a common mechanism underlying these hepatic defects.

One limitation of the present study is that the oral-i.v. double-tracer infusion technique measures the basal rate of splanchnic glucose uptake and cannot distinguish between hepatic and non-hepatic splanchnic tissues. However, because the majority of splanchnic glucose uptake ( $>90 \%)$ is by the liver [26], it is likely that the decreased basal glucose clearance in IFG is accounted for by a decrease in HGU. Because of the intensive nature of the procedures used in the present study, a relatively small number of individuals were included in the study. Another limitation of the study is that by chance all individuals with IFG had FPG concentration between 5.6 and $6.1 \mathrm{mmol} / \mathrm{l}$. However, the difference in mean FPG concentration between IFG and NGT groups was relatively large 
( $\sim 1 \mathrm{mmol} / \mathrm{l})$. A strength of our study comes about from the rate of basal glucose production being expressed per kg LBM; because of this a difference in body fat per cent between different individuals is unlikely to have contributed to the decreased basal splanchnic glucose uptake in individuals with IFG compared to those with NGT. Prior studies [29] have demonstrated that when normalised to LBM, hepatic glucose production is similar in obese and lean individuals over a wide BMI range.

In summary, the results of the present study demonstrate that reduced splanchnic glucose uptake during the fasting state causes elevated FPG concentration in individuals with IFG. They also show that the excessive rise in the plasma glucose concentration following a glucose load in IFG is due to impaired suppression of EGP. These findings underscore the importance of hepatic glucose metabolism in the pathogenesis of IFG.

Acknowledgements We thank L. Albarado and S. Balmer from the Diabetes Division, UTHSCSA (San Antonio, TX, USA), for their expert secretarial assistance in preparation of the manuscript. R. DeFronzo's salary is supported, in part, by the South Texas Veterans Health Care System. We would also like to thank CORPAK MedSystem (Buffalo Grove, IL, USA) for providing the CORTRAK instrument for placing the nasoduodenal tube.

Data availability The data will be made available once the study has been completed.

Funding This study was supported by a National Institutes of Health (NIH) grant (R01 DK097554-01) to MAG.

Duality of interest The authors declare that there is no duality of interest associated with this manuscript.

Contribution statement MA, CA, and JA participated in the discussion about the design of the study, generated the data, contributed to drafting the article and approved the final version. MAG designed the study, wrote the protocol, contributed to data generation and data analysis, wrote the manuscript and approved the final version. RAD reviewed and revised the study protocol, participated in the discussion about data interpretation, revised the manuscript and approved the final version. MAG is the guarantor of this work and, as such, had full access to all the data in the study and takes responsibility for the integrity of the data and the accuracy of the data analysis.

\section{References}

1. The Expert Committee on the Diagnosis and Classification of Diabetes Mellitus (1997) Report of the expert committee on the diagnosis and classification of diabetes mellitus. Diabetes Care 20:1183-1197

2. Unwin N, Shaw J, Zimmet P, Alberti KG (2002) Impaired glucose tolerance and impaired fasting glycaemia: the current status on definition and intervention. Diabet Med 19:708-723

3. Abdul-Ghani MA, Tripathy D, DeFronzo RA (2006a) Contributions of beta-cell dysfunction and insulin resistance to the pathogenesis of impaired glucose tolerance and impaired fasting glucose. Diabetes Care 29:1130-1139

4. Abdul-Ghani MA, Jenkinson CP, Richardson DK, Tripathy D, DeFronzo RA (2006b) Insulin secretion and action in subjectswith impaired fasting glucose and impaired glucose tolerance: results from the Veterans Administration Genetic Epidemiology Study. Diabetes 55:1430-1435

5. Weyer C, Bogardus C, Pratley RE (1999) Metabolic characteristics of individuals with impaired fasting glucose and/or impaired glucose tolerance. Diabetes 48:2197-2203

6. Bock G, Chittilapilly E, Basu R et al (2007) Contribution of hepatic and extrahepatic insulin resistance to the pathogenesis of impaired fasting glucose: role of increased rates of gluconeogenesis. Diabetes $56: 1703-1711$

7. Cali' AM, Bonadonna RC, Trombetta M, Weiss R, Caprio S (2008) Metabolic abnormalities underlying the different prediabetic phenotypes in obese adolescents. J Clin Endocrinol Metab 93:17671773

8. Bacha F, Lee S, Gungor N, Arslanian SA (2010) From pre-diabetes to type 2 diabetes in obese youth: pathophysiological characteristics along the spectrum of glucose dysregulation. Diabetes Care 33: 2225-2231

9. Bock G, Dalla Man C, Campioni M et al (2006) Pathogenesis of pre-diabetes: mechanisms of fasting and postprandial hyperglycemia in people with impaired fasting glucose and/or impaired glucose tolerance. Diabetes 55:3536-3549

10. Abdul-Ghani MA, Abdul-Ghani TA, Ali N, DeFronzo RA (2008) One hour plasma glucose concentration and the metabolic syndrome identify subjects at high risk for future type 2 diabetes. Diabetes Care 31:1650-1655

11. Abdul-Ghani MA, Williams K, DeFronzo RA, Stern MP (2007) What is the best predictor for future type 2 diabetes? Diabetes Care 30:1544-1548

12. Abdul-Ghani MA, Lyssenko V, Tuomi T, DeFronzo RA, Groop L (2009) Fasting versus post load plasma glucose concentration and the risk for future type 2 diabetes: results from the Botnia study. Diabetes Care 32:281-286

13. Cervera A, Wajcberg E, Sriwijitkamol A et al (2008) Mechanism of action of exenatide to reduce postprandial hyperglycemia in type 2 diabetes. Am J Physiol Endocrinol Metab 294:E846-E852

14. Polidori D, Sha S, Mudaliar S et al (2013) Canagliflozin lowers postprandial glucose and insulin by delaying intestinal glucose absorption in addition to increasing urinary glucose excretion: results of a randomized, placebo-controlled study. Diabetes Care 36:21542161

15. Camastra S, Muscelli E, Gastaldelli A et al (2013) Long-term effects of bariatric surgery on meal disposal and $\beta$-cell function in diabetic and nondiabetic patients. Diabetes 62:3709-3717

16. Rizza RA, Toffolo G, Cobelli C (2016) Accurate measurement of postprandial glucose turnover: why is it difficult and how can it be done (relatively) simply? Diabetes 65:1133-1145

17. Ter Horst KW, Gilijamse PW, Ackermans MT et al (2016) Impaired insulin action in the liver, but not in adipose tissue or muscle, is a distinct metabolic feature of impaired fasting glucose in obese humans. Metabolism 65:757-763

18. Perreault L, Man CD, Hunerdosse DM, Cobelli C, Bergman BC (2010) Incretin action maintains insulin secretion, but not hepatic insulin action, in people with impaired fasting glucose. Diabetes Res Clin Pract 90:87-94

19. Perreault L, Bergman BC, Playdon MC, Dalla Man C, Cobelli C, Eckel RH (2008) Impaired fasting glucose with or without impaired glucose tolerance: progressive or parallel states of prediabetes? Am J Physiol Endocrinol Metab 295:E428-E435

20. Tripathy D, Carlsson M, Almgren P et al (2000) Insulin secretion and insulin sensitivity in relation to glucose tolerance: lessons from the Botnia Study. Diabetes 49:975-980 
21. Hanefeld M, Koehler C, Fuecker K, Henkel E, Schaper F, Temelkova-Kurktschiev T (2003) Insulin secretion and insulin ?sensitivity pattern is different in isolated impaired glucose ?tolerance and impaired fasting glucose. Diabetes Care 26:868-874

22. Basu R, Barosa C, Jones J et al (2013) Pathogenesis of prediabetes: role of the liver in isolated fasting hyperglycemia and combined fasting and postprandial hyperglycemia. J Clin Endocrinol Metab 98:E409-E417

23. DeFronzo RA, Ferrannini E, Simonson DC (1989) Fasting hyperglycemia in non-insulin-dependent diabetes mellitus: contributions of excessive hepatic glucose production and impaired tissue glucose uptake. Metabolism 38:387-395

24. Jeng CY, Sheu WH, Fuh MM, Chen YD, Reaven GM (1994) Relationship between hepatic glucose production and fasting plasma glucose concentration in patients with NIDDM. Diabetes 43: $1440-1444$
25. Jani R, Molina M, Matsuda M et al (2008) Decreased non-insulindependent glucose clearance contributes to the rise in fasting plasma glucose in the nondiabetic range. Diabetes Care 31:311-315

26. RA DF Lilly lecture 1987 . The triumvirate: beta-cell, muscle, liver. A collusion responsible for NIDDM. Diabetes 37(667-687):1988

27. DeFronzo RA, Ferrannini E, Hendler R, Felig P, Wahren J (1983) Regulation of splanchnic and peripheral glucose uptake by insulin and hyperglycemia in man. Diabetes 32:35-45

28. Perreault L, Færch K, Kerege AA, Bacon SD, Bergman BC (2014) Hepatic glucose sensing is impaired, but can be normalized, in people with impaired fasting glucose. J Clin Endocrinol Metab 99:E1154-E1162

29. Natali A, Toschi E, Camastra S, Gastaldelli A, Groop L, Ferrannini E (2000) Determinants of postabsorptive endogenous glucose output in non-diabetic subjects. European Group for the Study of Insulin Resistance (EGIR). Diabetologia 43:1266-1272 